\title{
Transthoracic vertebrectomy for metastatic spinal tumors
}

\author{
Ziya L. Gokaslan, M.D., Julie E. York, M.D., Garrett L. Walsh, M.D., Ian E. McCutcheon, M.D., Frederick \\ F. Lang, M.D., Joe B. Putnam, Jr., M.D., David M. Wildrick, Ph.D., Stephen G. Swisher, M.D., Dima \\ Abi-Said, Ph.D., and Raymond Sawaya, M.D.
}

Departments of Neurosurgery and Thoracic and Cardiovascular Surgery, The University of Texas M. D. Anderson Cancer Center, Houston, Texas

Anterior approaches to the spine for the treatment of spinal tumors have gained acceptance; however, in most published reports, patients with primary, metastatic, or chest wall tumors involving cervical, thoracic, or lumbar regions of the spine are combined. The purpose of this study was to provide a clear perspective of results that can be expected in patients who undergo anterior vertebral body resection, reconstruction, and stabilization for spinal metastases that are limited to the thoracic region.

Outcome is presented for 72 patients with metastatic spinal tumors who were treated by transthoracic vertebrectomy at The University of Texas M. D. Anderson Cancer Center. The predominant primary tumors included renal cancer in 19 patients, breast cancer in 10, melanoma or sarcoma in 10, and lung cancer in nine patients. The most common presenting symptoms were back pain, which occurred in $90 \%$ of patients, and lower-extremity weakness, which occurred in $64 \%$ of patients. All patients underwent transthoracic vertebrectomy, decompression, reconstruction with methylmethacrylate, and anterior fixation with locking plate and screw constructs. Supplemental posterior instrumentation was required in seven patients with disease involving the cervicothoracic or thoracolumbar junction, which was causing severe kyphosis. After surgery, pain improved in 60 of 65 patients. This improvement was found to be statistically significant $(p<0.001)$ based on visual analog scales and narcotic analgesic medication use. Thirty-five of the 46 patients who presented with neurological dysfunction improved significantly $(\mathrm{p}<0.001)$ following the procedure. Thirty-three patients had weakness but could ambulate preoperatively. Seventeen of these 33 regained normal strength, 15 patients continued to have weakness, and one patient was neurologically worse postoperatively. Of the 13 preoperatively nonambulatory patients, 10 could walk after surgery and three were still unable to walk but showed improved motor function. Twenty-one patients had complications ranging from minor atelectasis to pulmonary embolism. The 30-day mortality rate was $3 \%$. The 1 -year survival rate for the entire study population was $62 \%$.

These results suggest that transthoracic vertebrectomy and spinal stabilization can improve the quality of life considerably in cancer patients with spinal metastasis by restoring or preserving ambulation and by controlling intractable spinal pain with acceptable rates of morbidity and mortality.

Key Words * transthoracic approach * vertebrectomy * spine * thoracic spine * metastasis * tumor

In 1998, an estimated 1.2 million new cancer cases will be diagnosed.[24] In North America, approximately 18,000 new cases of metastasis to the spine are diagnosed each year.[42] For example, from 1984 to 1994, 113,831 new patients were referred to The University of Texas M. D. Anderson Cancer Center (UTMDACC) for treatment of various neoplasms (Table 1). Metastatic disease was found in the spinal columns of 11,884 of these patients. Such patients often require urgent treatment to alleviate the intractable pain the tumors cause and to address spinal cord 
compromise resulting from direct compression by tumor, retropulsion of vertebral fragments, or severe kyphosis.[42] Medical care of these patients is expensive, and costs may be increased if the tumor produces paresis or paraplegia.

\begin{tabular}{|c|c|c|}
\hline \multicolumn{3}{|c|}{$\begin{array}{r}\text { TABLE } 1 \\
\text { FREQUENCES OF PRMARY CANCERS }\end{array}$} \\
\hline $\begin{array}{l}\text { Primary } \\
\text { Cancer Site }\end{array}$ & $\begin{array}{c}\text { No. of } \\
\text { Cases }[\%]\end{array}$ & $\begin{array}{l}\text { No. of Spinal } \\
\text { Metastases [\%] }\end{array}$ \\
\hline $\begin{array}{l}\text { all sites } \\
\text { breast } \\
\text { blood } \\
\text { lung } \\
\text { skin } \\
\text { colon } \\
\text { prostate } \\
\text { urinary tract } \\
\text { mouth } \\
\text { unknown } \\
\text { ovary } \\
\text { uterus } \\
\text { pancreas } \\
\text { bone } \\
\text { other }\end{array}$ & $\begin{array}{r}113,831 \\
13,977(12.3) \\
12,907(11.3) \\
10,568(9.3) \\
10,844(9.5) \\
7,107(6.2) \\
6,975(6.1) \\
5,692(5.0) \\
5,174(4.5) \\
4,099(3.6) \\
2,916(2.6) \\
2,224(2.0) \\
1,637(1.4) \\
1,167(1.0) \\
28,544(25.1)\end{array}$ & $\begin{array}{r}11,884 \\
3,592(25.7) \\
1,213(9.4) \\
2,410(22.8) \\
369(3.4) \\
185(2.6) \\
1,137(16.3) \\
478(8.4) \\
72(1.4) \\
344(8.4) \\
17(0.6) \\
16(0.7) \\
10(0.6) \\
14(1.2) \\
2,027(7.1)\end{array}$ \\
\hline $\begin{array}{l}\text { "Patient po } \\
\text { tumor regist" } \\
\text { matics. }\end{array}$ & $\begin{array}{l}\text { as identifie } \\
\text { ed by the }\end{array}$ & $\begin{array}{l}\text { a search of the } \\
\text { of Medical In for- }\end{array}$ \\
\hline
\end{tabular}

Malignancies of lung, breast, and prostate show a high frequency of metastasis to the spine. The thoracic region of the spine is most commonly involved with metastatic disease ( $70 \%$ of cases), whereas the cervical (10\% of cases) and lumbar (20\% of cases) regions are less frequently affected. The majority of spinal metastases $(80 \%)$ involve the vertebral bodies rather than the posterior vertebral elements.[34]

Patients with spinal metastases most commonly present with pain as their chief complaint. At the time of diagnosis, neurological compromise is seen in most patients.[14] Three types of pain are encountered in cancer patients who have metastatic spinal column involvement. These are local pain, axial spinal pain, and radicular pain. Local pain is constant and generally does not worsen with movement or improve with recumbency. Imaging studies in patients with local pain usually reveal enlargement of the vertebral body without evidence of vertebral body collapse or spinal deformity. The cause of this pain has been attributed to periosteal stretching of the vertebral body by the tumor mass.

Axial spinal pain is a significant cause of morbidity. It is a mechanical pain resulting from a structural abnormality in the spinal column. This type of pain worsens with movement and is relieved with recumbency. Imaging studies performed in patients having axial pain usually reveal vertebral body collapse and/or spinal deformity. Spinal stabilization is normally very effective in relieving this type of pain. Radiation therapy is of no benefit in alleviating discomfort in patients with axial pain.

Radicular pain is related to compression of a nerve root. It is usually constant, but may be worsened or relieved with movement. The pain occurs in a dermatomal distribution and is usually associated with dysesthesia.

Depending on the cause of the compression, the nerve root may need to be decompressed either surgically, to remove pressure from a bone fragment or tumor mass, or with the use of chemotherapy and/or radiation treatment, in the case of chemosensitive or radiosensitive tumors.

During the last few years we have implemented an aggressive, multidisciplinary surgical approach to neoplasms found at all spinal levels, both for intervention in patients with confirmed or impending neurological compromise from spinal cord compression and for palliation of severe, intractable pain that is difficult to alleviate, even with narcotic analgesic medications. The anterior (transthoracic) approach provides the most direct route to the spinal 
column for decompression, reconstruction, and stabilization, and is now the method we prefer for resecting tumors largely confined to thoracic vertebral bodies. Among its other advantages relative to posterior approaches, the anterior approach permits minimal removal of uninvolved bone, rapid removal of tumor, effective reconstruction of the weight-bearing anterior column, short-segment fixation, and improved wound healing. The purpose of this study was to describe our surgical procedure and its results with respect to pain relief, neurological recovery, and risk of complications in patients with metastatic tumors who underwent transthoracic vertebrectomy via a sternotomy, thoracotomy, or thoracoabdominal approach.

\section{CLINICAL MATERIAL AND METHODS}

\section{Patient Population}

We performed 523 spinal operations in 400 patients with cancer from February 1, 1994 through July 31, 1997 at UTMDACC. Seventy-two patients with metastatic disease involving the thoracic spine underwent vertebrectomies via the transthoracic approach and represent the study population of this paper. Certain characteristics of 47 of these patients have already been published.[42] Indications for surgery were symptomatic spinal cord compression and/or intractable axial spinal pain resulting from spinal instability. All patients had an estimated life expectancy that exceeded 3 months.

The patients' records were retrospectively reviewed, and data were collected on patient age, gender, date of initial diagnosis, histological characteristics of the primary tumor, and date of onset of symptoms referable to spinal disease. Medical treatment (chemotherapy, radiation therapy, or both) prior to the surgical consultation was recorded, in addition to the number of extraspinal metastases at the time of the patients' spinal surgery. The following surgical data were obtained: use of preoperative tumor embolization, intraoperative blood loss, method of spinal stabilization, postoperative complications (within 1 month), number of days chest tubes were required, and length of postoperative hospital stay. Postoperatively, patients were evaluated at 1 month and thereafter at 3-month intervals for the 1st year. Subsequently, they were evaluated every 6 months. Plain x-ray films (anteroposterior and lateral) were obtained at each visit. Patients underwent spinal magnetic resonance (MR) imaging every 3 to 6 months as part of their systemic workup.

Postoperative pain and neurological status were evaluated at each patient's 1-month follow-up visit because this was long enough for incisional pain to resolve but short enough for an assessment of pain and narcotic usage to reflect only the effects of the recent operation. (In other words, at this point patients were unlikely to have acquired other metastases in the spine or at distant sites that might have clouded the picture.) We used visual analog pain scales and recorded narcotic analgesic medication usage before and after surgery to assess pain response. Postoperative pain was graded as "worse," "no change," "improved," or "complete resolution" based on the patient's pain rating. Additionally, the type of pain medication used both pre- and postoperatively was classified as shown in Table 2.

\begin{tabular}{|c|}
\hline TABLE 2 \\
CLASSIFICATION OF ANALGESC MED KATIONS USED IN PATIENTS WITH \\
METASTATC SPINAL TUMORS
\end{tabular}

The Frankel scale[13] was used for pre- and postoperative assessment of each patient's neurological status including motor, sensory, and autonomic function (Table 3). Each patient's pain rating, use of analgesic medications, and neurological function were recorded immediately prior to surgery and at the 1-month follow-up appointment. Length of follow up was calculated from the date of surgery to the patient's most recent clinic appointment. The Kaplan-Meier[21] method was used to estimate postoperative survival. 
TABLE 3

MODIFIED FRANKEL NEUROLOGICAL FUNCTIONAL CLASSFICATION

\begin{tabular}{|c|c|}
\hline Grade & Description \\
\hline A & no motor or sensory function \\
\hline $\mathrm{B}$ & preserved sensation only no motor function \\
\hline $\mathrm{c}$ & nonam bulatory, whe elchair bound, some motor function \\
\hline a & bo mel or thadder paral ysis \\
\hline $\mathrm{b}$ & neurogenic bomel or bladder \\
\hline c & woluntary normal bowel or tiadder function \\
\hline D & am bulatory but $w /$ neurological sym ptoms \\
\hline 1 & requires malker \\
\hline 2 & requires cane \\
\hline 3 & can walk independenty \\
\hline a & bowel or bladder paral ysis \\
\hline b & neurogenic bladder \\
\hline c & $\begin{array}{l}\text { woluntary normal boinel or tiadder function but } \mathrm{w} / \text { some } \\
\text { sensory loss or simotoms }\end{array}$ \\
\hline $\mathrm{E}$ & normal neurological functions \\
\hline
\end{tabular}

Interventional radiologists performed tumor embolization 18 to 24 hours before surgery, when appropriate, as determined by the tumor's histological characteristics and vascularity. This was generally performed in patients with renal cell carcinoma and, occasionally, in those with other vascular metastatic tumors. All patients received standard perioperative antibiotic agents and subcutaneous heparin for deep vein thrombosis prophylaxis.

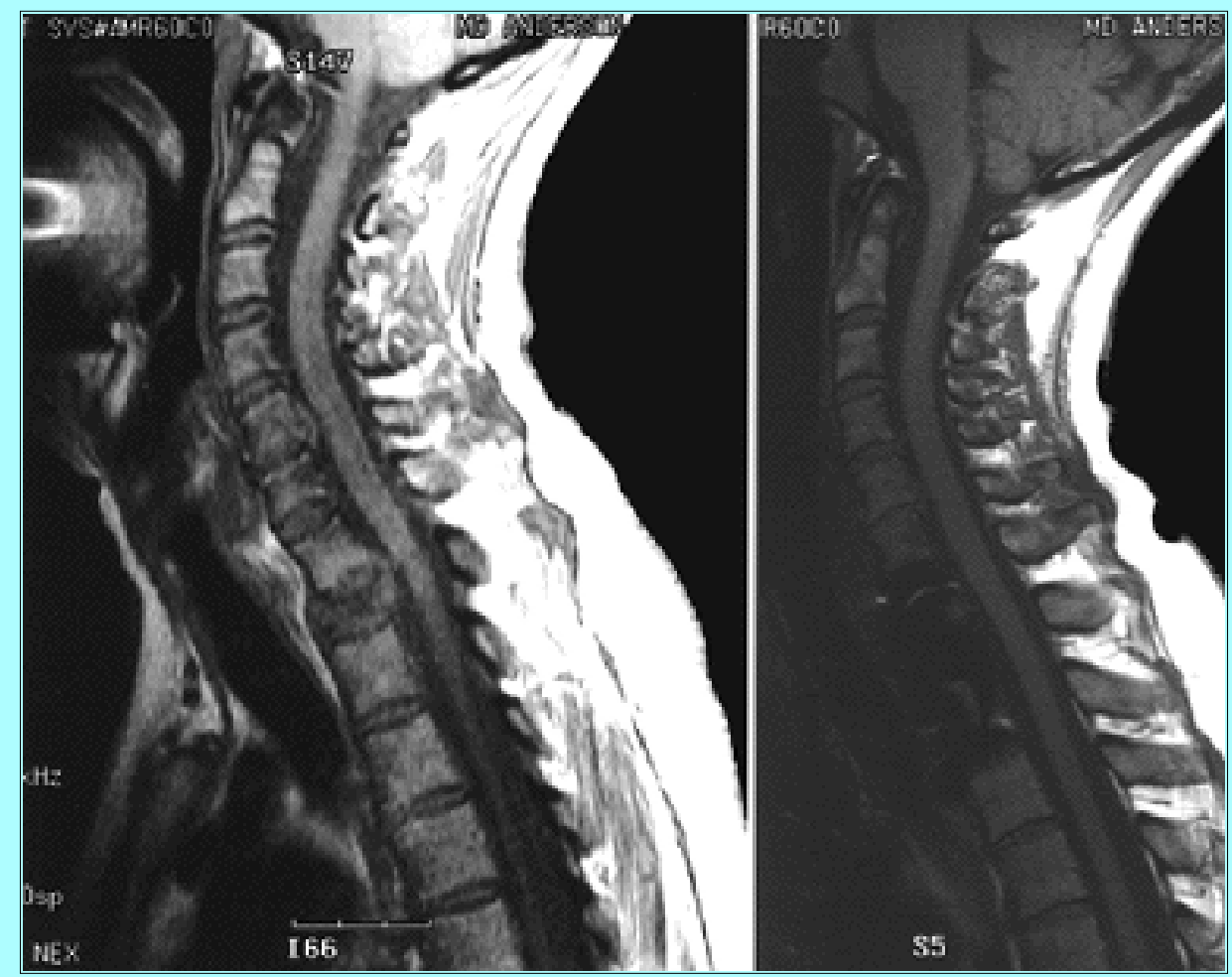

Fig. 1. Preoperative (left) and postoperative (right) MR images obtained in a patient with a metastatic T-1 lesion (gastric carcinoma). The preoperative image shows vertebral body collapse and kyphotic angulation. The postoperative image reveals a well-decompressed spinal canal with correction of the kyphotic deformity. A T-1 vertebrectomy, anterior reconstruction with methylmethacrylate, and plating were performed via an anterior cervical approach combined with a sternotomy.

In the case of lesions located at T-1 or T-2, we performed a combined sternotomy and anterior neck dissection (Figs. 1 and 2). The favored entry site was the left side of the neck, because approaching the spine from the patient's right side increases the risk of stretch injury to the right recurrent laryngeal nerve. 


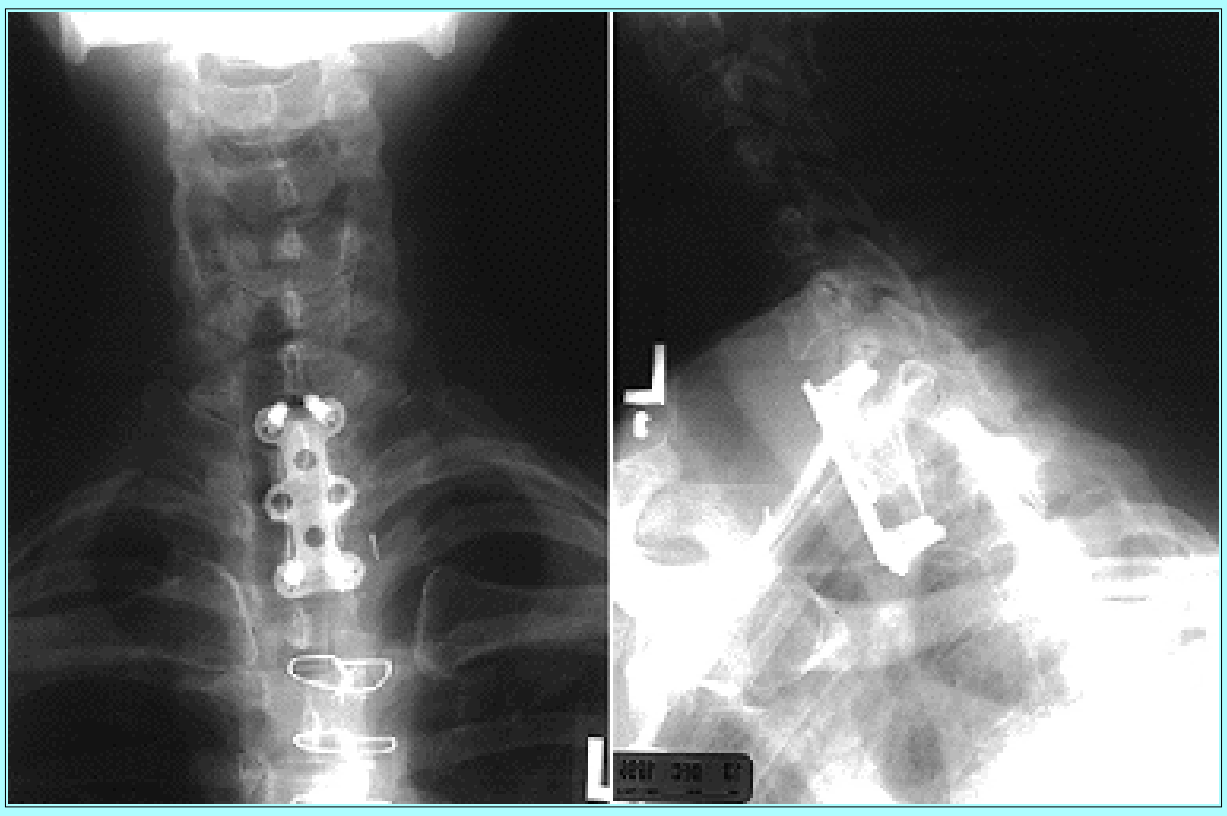

Fig. 2. Anteroposterior (left) and lateral (right) x-ray films of the cervicothoracic spine of the patient in Fig. 1, showing the cervical locking plate and screw construct as well as the sternal wires.

For exposure of the high thoracic region involving T-3 and T-4, the "trap door" approach was used. This approach combines a standard anterior neck dissection with both a partial median sternotomy and an anterolateral thoracotomy.

For lesions involving T5-10, posterolateral thoracotomy was performed after placement of a single-lumen endotracheal tube. Here, the right hemithorax was the preferred site of entry; however, tumors with a large extravertebral extension were approached on the side having the bulk of tumor. In patients who have had previous chest operations, we prefer an approach via the contralateral hemithorax to avoid problems with prolonged postoperative air leaks that would require an extended duration of chest tube placement and could increase the risk of contaminating the spinal hardware. For lesions involving T-5 and T-6, the fifth rib was removed. For T-7 and $\mathrm{T}-8$, the rib located one level above the tumor epicenter (6th or 7th, respectively) was removed. For T9-11 tumor involvement, the rib two levels above (seventh, eighth, or ninth rib, respectively) was removed. The thoracoabdominal approach was chosen for treating metastatic lesions occurring in T-11 and T-12.

Surgical resection began immediately in cases in which the tumor was grossly visible within the chest cavity; however, when the identity of the vertebral lesion was in doubt, an intraoperative x-ray film was obtained by using a localizing spinal needle to confirm the spinal level. The parietal pleura overlying the area of interest was incised and reflected ventrally. We identified the segmental vessels at the vertebrectomy site and at the levels above and below it. These vessels were doubly ligated and transected. We performed discectomies rostral and caudal to the vertebrectomy site using a No. 15 blade scalpel, pituitary rongeurs, and curettes. Leksell rongeurs were used to begin removal of the vertebral body; we then switched to a high-speed power drill with diamond or cutting burr attachments until we reached the posterior longitudinal ligament, which was incised and dissected away from the dural sac. We always opened the posterior longitudinal ligament and visualized the nerve roots exiting at the level of the resection to ensure complete decompression of the thecal sac. In situations in which the tumor was too solid for aspiration by ordinary suction devices but was too soft for the high-speed drill, we used an ultrasonic aspirator (Cavitron Ultrasonic Aspirator; ValleyLab, Inc., Boulder, CO). When resecting was finished, we fully visualized the end plates of the vertebral bodies above and below the level of resection and determined them to be free of disc material and gross tumor (Fig. 3-1). 


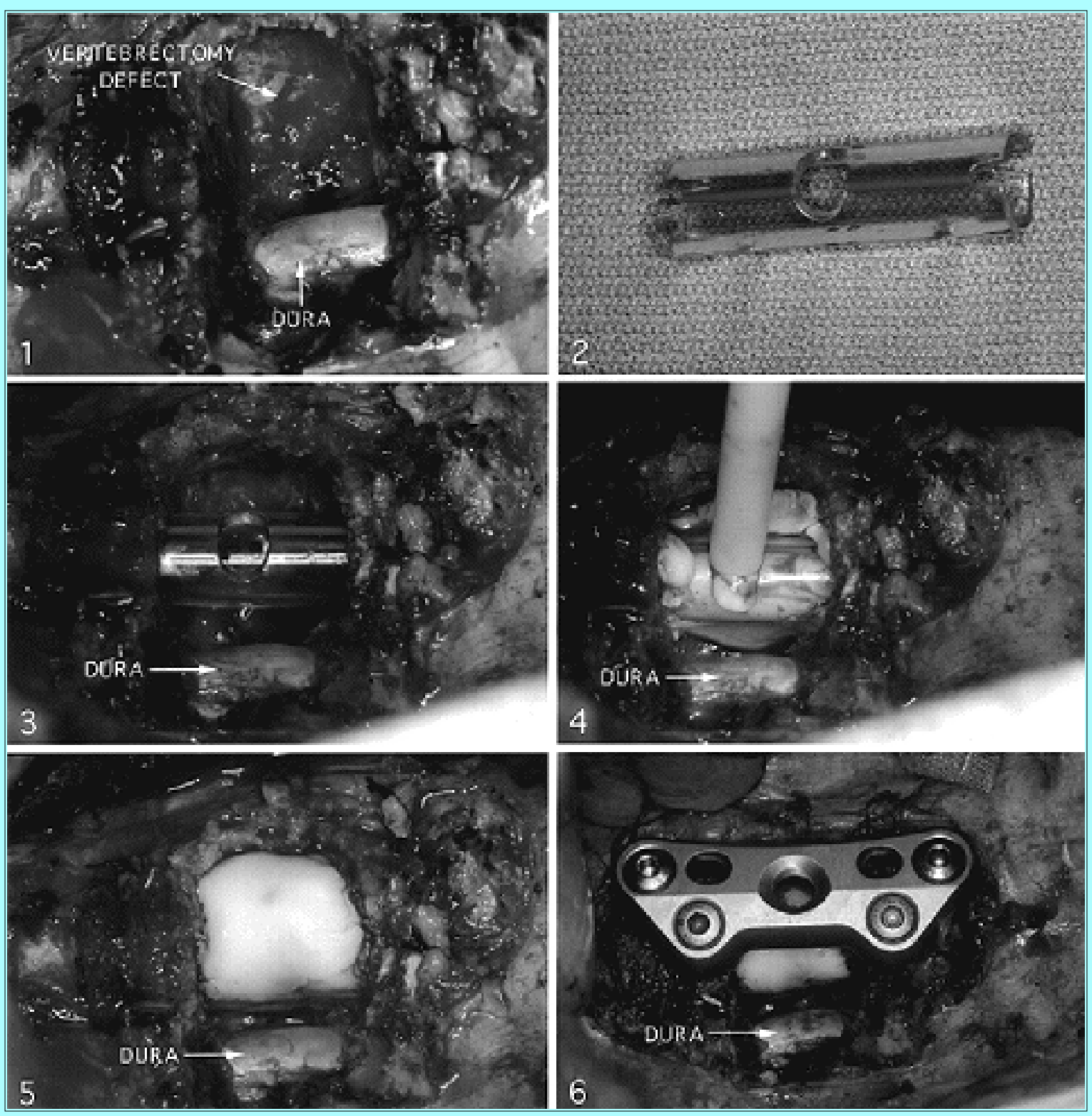

Fig. 3. Intraoperative photographs obtained in a patient with a metastatic lesion of T-7 from breast cancer. 1: The vertebrectomy defect and decompressed thecal sac are both visualized. 2: A No. 36 French chest tube fashioned for vertebral reconstruction. 3: The same chest tube spanning the vertebrectomy defect and embedded in the vertebral bodies caudally and rostrally. 4: Injection of methylmethacrylate into the chest tube. 5: Final construct showing solidified acrylic filling the vertebrectomy defect. 6: For additional stabilization, an anterior thoracolumbar locking plate and screw construct was used in this patient.

Following the vertebrectomy, we used a right-angled drill attachment to create a cylindrical central defect in the vertebrae above and below the resection site that extended into the bone a distance equaling $75 \%$ of the height of each vertebra, as described by Errico and Cooper.[12] We preserved a portion of each vertebra and the remaining endplate to maintain the structural integrity of the bone and to provide anchorage for fixation screws. A No. 36 French chest tube was shortened to a length equaling the total height of the space created by the vertebrectomy defect plus the length of the holes drilled above and below (Fig. 3-2). We cut a hole in the center of this tube for injection of methylmethacrylate and made additional holes at each end of the tube to permit air to escape during injection of the cement. The tube was positioned so that it spanned the vertebrectomy defect (Fig. 3-3). We were careful to prevent contact between the cement and the thecal sac during injection and solidification (Fig. 3-4-5) because heat released during the polymerization reaction can injure the cord and expansion of the acrylic cement can compress it. We irrigated the construct with tepid saline during this step to minimize the heat released to surrounding tissues. 
Thoracolumbar locking plate and screw constructs were used to provide additional anterior spinal stabilization to prevent distraction failure with all vertebrectomies below T-6 (Fig. 3-6). For fixation of lesions above T-6, a cervical locking plate and screw construct was used (Synthes USA, Paoli, PA; Fig. 2). In seven patients (10\%) in whom severe kyphosis was present (Fig. 4) or in whom the metastasis resided in a junctional (cervicothoracic or thoracolumbar) zone, posterior hooks, rods, pedicle screws, or wires were used as needed (Fig. 5). External orthoses were not used in any patient.

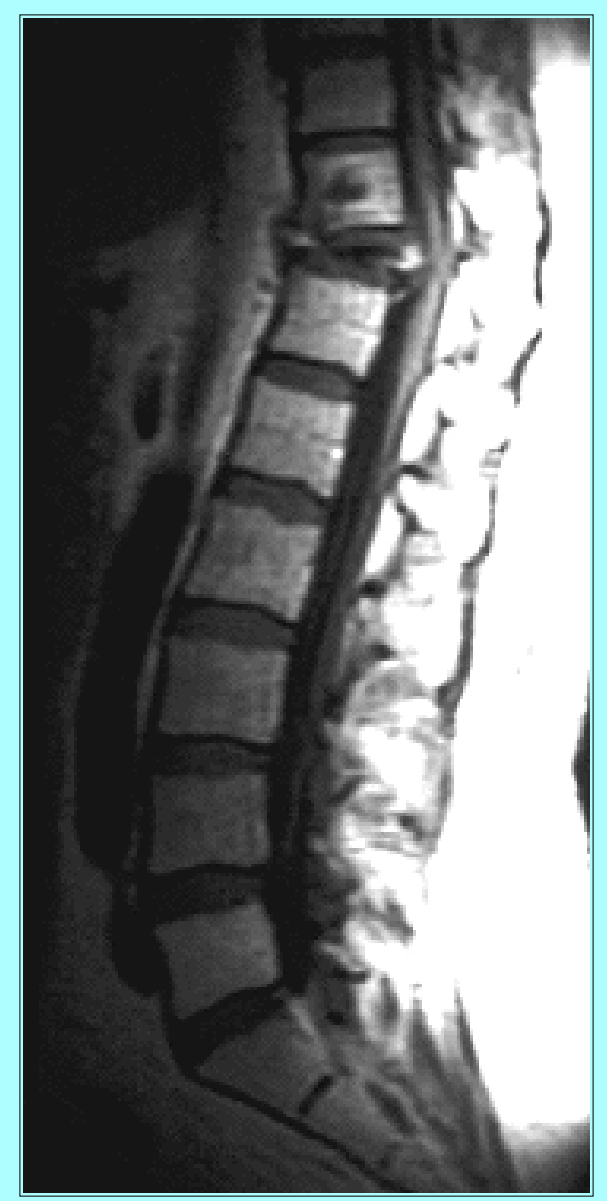

Fig. 4. Preoperative sagittal MR image showing a metastatic breast cancer lesion at T-11 with severe kyphosis and spinal cord compression and a central vertebral body lesion at T-10. The patient was wheelchair bound. 


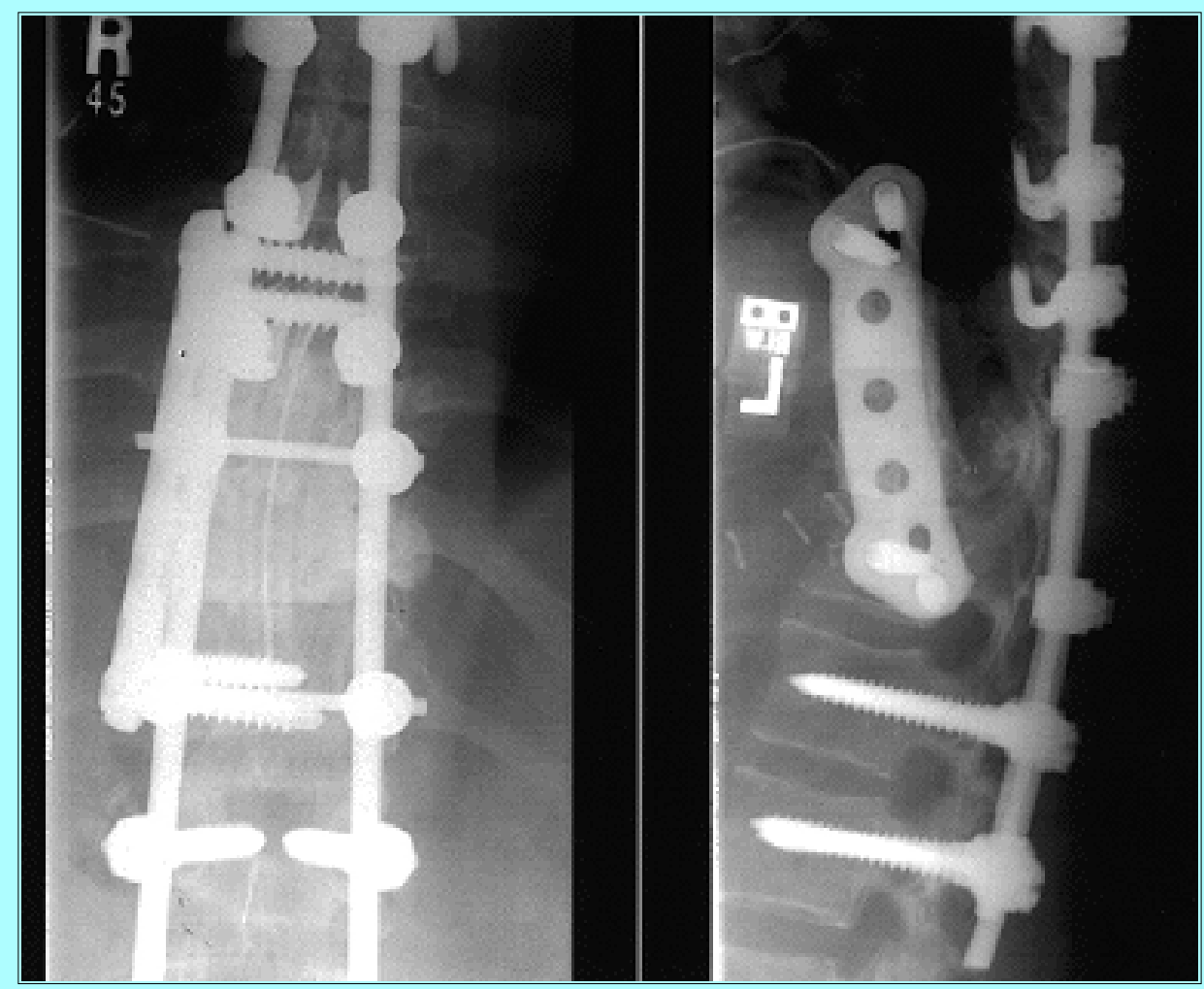

Fig. 5. Postoperative anteroposterior (left) and lateral (right) plain x-ray films demonstrating spinal instrumentation used in the patient in Fig. 4, who underwent vertebrectomy of T-10 and T-11 and reconstruction with methylmethacrylate via a thoracoabdominal approach. In addition to the anterior thoracolumbar plate and screws, supplements posterior fixation (including hooks and pedicle screws) was used because the lesion was located at the thoracolumbar junction and produced severe preoperative kyphosis. Postoperatively, the patient was able to walk independently.

We placed one or two chest tubes (No. 32 or 36 French) in the thoracic cavity and used a standard procedure for chest closure. The chest tubes were not removed until the drainage for a 24-hour period was less than 150 to 200 $\mathrm{ml}$.

\section{RESULTS}

Seventy-two patients underwent surgery via an anterior approach for metastatic disease involving the thoracic spine between February 1, 1994 and July 31, 1997. Among the 24 women and 48 men the median age was 56 years (range 19-78 years). Forty-six (64\%) of these patients suffered from weakness in the lower extremities, and 65 (90\%) of 72 reported pain, either local or radicular pain with no spinal instability (23 patients), or axial spinal pain resulting from spinal instability (42 patients). Twenty-two patients who had no previous history of cancer presented initially with pain only. In the remaining 50 patients with a known history of cancer, the median time to symptomatic presentation from primary tumor discovery was 19 months (range 0-15 years).

Primary tumors in the study group included: renal cell carcinoma in 19 patients, breast cancer in 10, melanoma or sarcoma in 10, lung cancer in nine, head and neck cancer in six, prostate cancer in two, and multiple myeloma in two patients; the primary tumors in the remaining 14 patients fell into other categories. These patients were recognized as having an average of 2.5 extraspinal sites of metastatic cancer (range $0-15$ ) at the time of their spinal surgery.

Prior to surgical consultation, an initial attempt was made to treat the spinal disease medically in 53 patients: 10 were treated with chemotherapy alone, 10 received radiation therapy alone, and 33 patients were treated with both chemotherapy and radiation therapy before surgery (Table 4). Twelve patients underwent preoperative tumor embolization (10 with renal cell carcinomas, one with a hemangiopericytoma, and one with a thyroid carcinoma metastasis). The remaining 19 patients were referred directly to surgery by the medical or radiation oncologist, and 
no other treatment modalities for the spinal disease were attempted before surgery.

\begin{tabular}{|c|c|c|c|c|}
\hline $\begin{array}{l}\text { PREOPERATNE MED } \\
\text { UNDERWENT TRAN }\end{array}$ & $\begin{array}{l}\text { TABLI } \\
\text { THER } \\
\text { HORAC } \\
\text { TATKC }\end{array}$ & $\begin{array}{l}4 \\
\text { Y USED } \\
\text { VERTEE } \\
\text { UMORS* }\end{array}$ & $\begin{array}{l}\text { IN PATIE } \\
\text { SRECTOM }\end{array}$ & $\begin{array}{l}\text { NTS WHO } \\
\text { FOR }\end{array}$ \\
\hline $\begin{array}{l}\text { Type of } \\
\text { Primary Tumor }\end{array}$ & $\begin{array}{l}\text { RT } \\
\text { Orly }\end{array}$ & $\begin{array}{c}\text { Chemo } \\
\text { Orly }\end{array}$ & $\begin{array}{l}\text { RT \& } \\
\text { Chemo } 0\end{array}$ & Neither \\
\hline $\begin{array}{l}\text { all tumors } \\
\text { renal oell } \\
\text { treast } \\
\text { lung } \\
\text { melanomasarooma }\end{array}$ & $\begin{array}{r}10 \\
2 \\
0 \\
2 \\
2\end{array}$ & $\begin{array}{r}10 \\
4 \\
0 \\
0 \\
3\end{array}$ & $\begin{array}{r}33 \\
8 \\
9 \\
4 \\
2\end{array}$ & $\begin{array}{r}19 \\
5 \\
1 \\
3 \\
3\end{array}$ \\
\hline $\begin{array}{l}\text { "Ereakdown is gi iv } \\
\text { mon tumors. Abbre } \\
=\text { radiation therapy. }\end{array}$ & 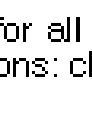 & $=$ & for & $\begin{array}{l}\text { t } \infty m- \\
\text { PY; RT }\end{array}$ \\
\hline
\end{tabular}

Transthoracic approaches varied according to spinal level. Six patients with lesions at T1-2 underwent sternotomy; two with T3-4 tumors were approached via a "trap door" exposure; 47 patients with T5-10 involvement were treated with a posterolateral thoracotomy; and 17 with T11-12 lesions underwent a thoracoabdominal approach. Forty-five patients underwent single-level vertebrectomies, 21 required two-level vertebrectomies, and six underwent vertebrectomies at three contiguous levels.

Total blood loss ranged from $100 \mathrm{ml}$ to $31 \mathrm{~L}$ (median $850 \mathrm{ml}$ ). In the entire study population, the median blood loss per level surgically treated was $700 \mathrm{ml}$ (range $50-15,500 \mathrm{ml}$ ). In the case of patients with renal cell disease, the median blood loss per level showed more than a twofold increase (median $1750 \mathrm{ml}$; range 300-15,500 ml).

We customarily admitted patients to our surgical intensive care unit immediately after surgery. Thirty-five patients were extubated on the day of surgery in either the operating room or recovery room. The median chest tube requirement was 4 days (range 1-26 days). Within 24 hours of chest tube removal, patients were either discharged or moved to our in-hospital rehabilitation unit if they needed extended physiotherapy. Postoperative hospital stays ranged from 4 to 55 days (median 10 days).

We observed a total of 24 surgically related complications (14 major and 10 minor) in 21 patients. Major complications included epidural hematoma in three patients, pneumonia in three, gastrointestinal bleeding in two, cerebrospinal fluid leak in two, renal failure in two, cecal perforation in one patient, and pulmonary embolism in one patient. Minor complications included atelectasis, ileus, atrial fibrillation, pleural effusion, and superficial wound infection, each of which was observed in two patients. These complications resulted in the only two deaths recorded in the study, giving an overall 30-day mortality rate of two (3\%) of 72 . One death resulted from a spontaneous cecal perforation with sepsis in a patients with multiple myeloma who was receiving high-dose steroid medication, and one occurred in a patient who died of respiratory failure following T-7 and T-12 vertebrectomies for metastatic lung cancer.

Three patients experienced a decrease in neurological function following embolization of their spinal metastases prior to surgical resection. One patient experienced transient worsening in function, but the other two patients sustained permanent deficits (one changed from Frankel E to $\mathrm{Cb}$ and the other from Frankel E to D1a). Three patients experienced postoperative deterioration in neurological function. Imaging studies in these patients suggested the presence of epidural hematomas; however, at subsequent reoperation, only one patient was found to have a significant hematoma compressing the spinal cord. That patient remained neurologically worse, whereas the other two patients returned to their original preoperative neurological status; thus, the permanent neurological complication rate in our series was one $(1.4 \%)$ of 72 patients. There were no instrument- or graft-related complications. Recurrence requiring reoperation occurred in six patients at the original surgical site and in two patients at a distant site.

The overall 1-year survival rate was 62\% (Fig. 6 upper, Kaplan-Meier estimate). Figure 6 lower illustrates 
Kaplan-Meier curves for the four most commonly encountered tumors. The 1-year survival rates for renal cell, breast, and lung cancer were $65 \%, 63 \%$, and $55 \%$, respectively, and that for melanoma or sarcoma was $52 \%$. The mean duration of follow up was 11 months, with an $88 \%$ level of follow up achieved at 6 months and $84 \%$ at 1 year. Nineteen patients were followed for more than 2 years with no evidence of hardware loosening or impending failure.
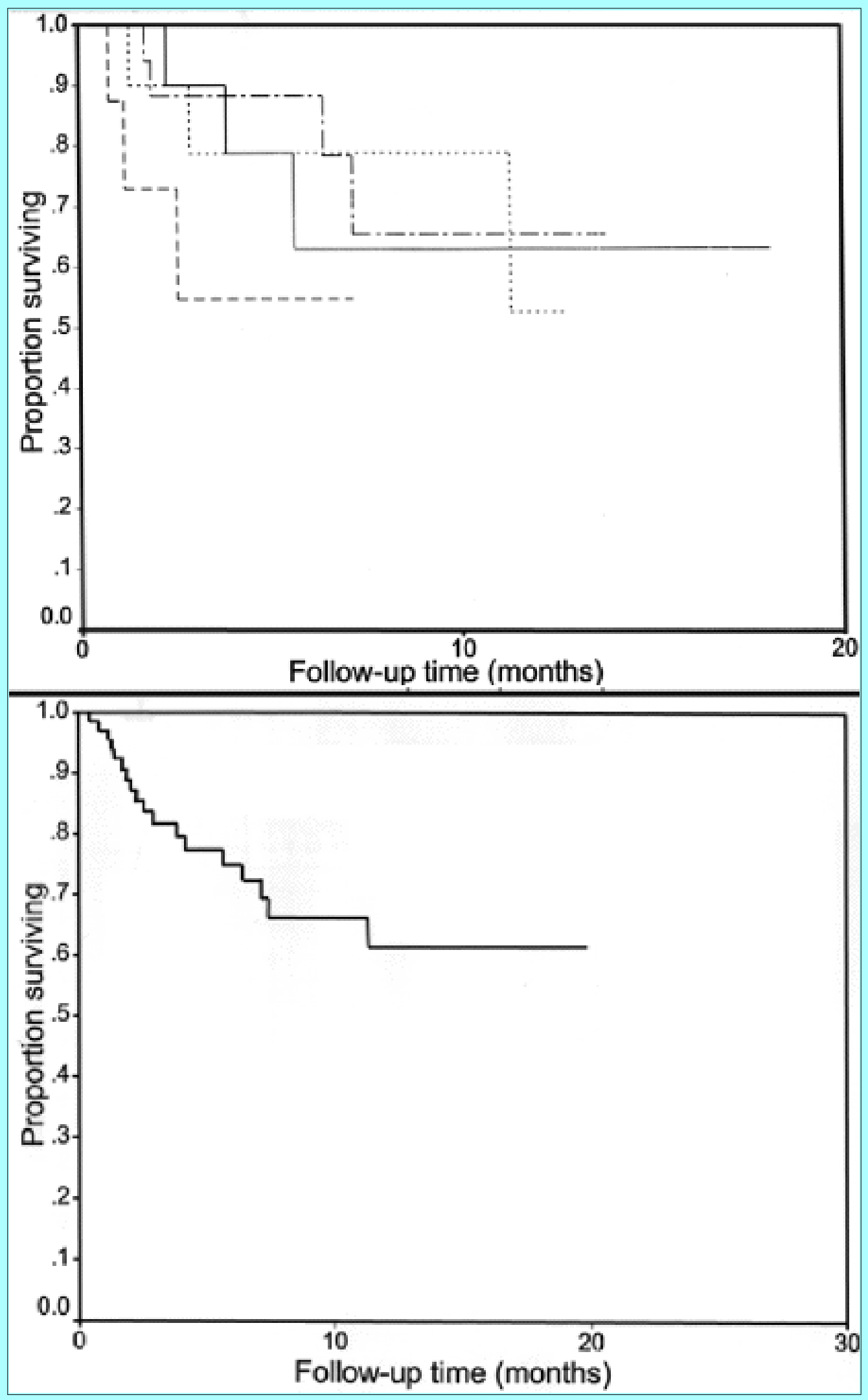

Fig. 6. Upper: Graph displaying the overall Kaplan-Meier survival curve for 72 patients who underwent transthoracic vertebrectomy for metastatic disease. Lower: Graph comparing survival by 
type of tumor for the four most commonly encountered histological types: renal cell

(long-and-short-dash line), breast (unbroken line) lung (long-dash line) cancer, and melanoma or

sarcoma (short-dash line). Survival curves were drawn using the Kaplan-Meier product limit method.

Of the 65 patients who presented with pain as a result of spinal metastasis (Fig. 7), complete resolution was achieved in 15 (23\%); pain was significantly improved by the operation in $45(69 \%)$ and unchanged or worsened in five (8\%). Thus, $60(92 \%)$ of 65 patients showed completely or greatly reduced pain postoperatively $(\mathrm{p}<0.001$, Wilcoxon signed-rank test). Pain control at the operative site was durable (except in patients who had recurrence and underwent a second operation).

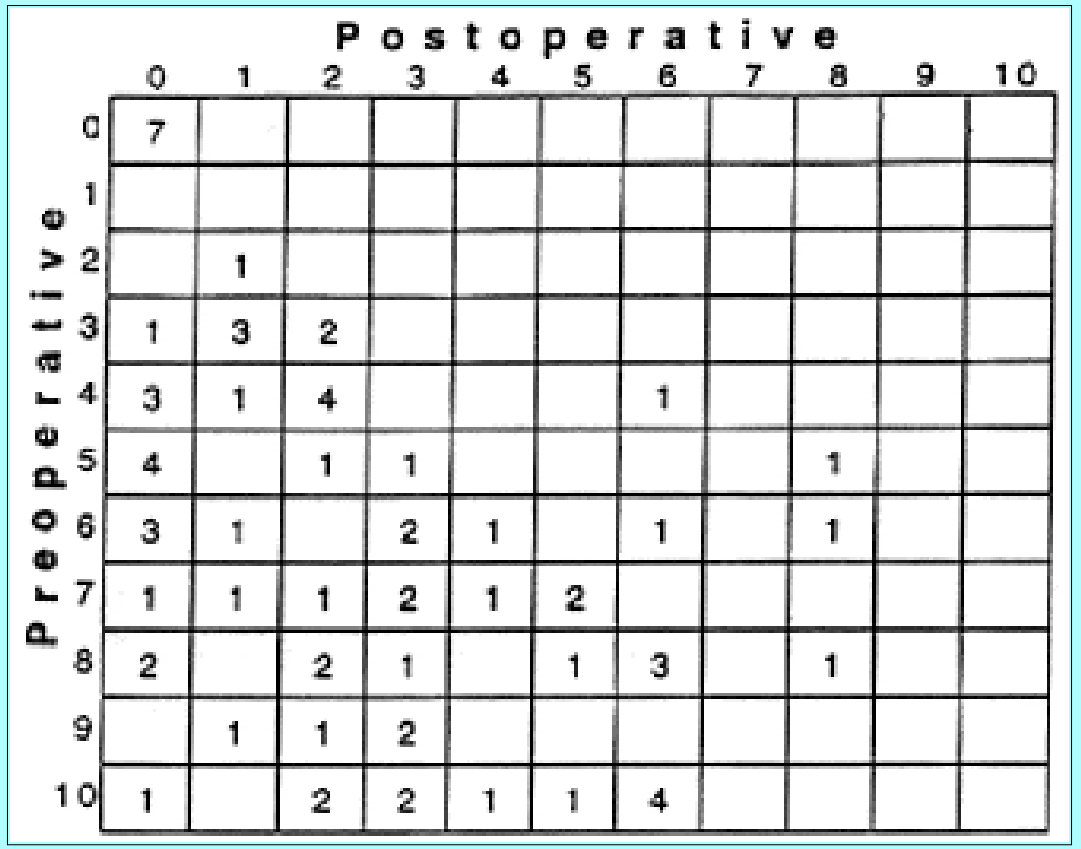

Fig. 7. Diagram indicating the relationship between the preoperative and 1-month postoperative pain assessment using the visual analog scale. Values within boxes indicate numbers of patients with corresponding pain scores in the pre- and postoperative periods. A shift in the number of patients with high preoperative pain scores to low postoperative pain scores signifies an improvement in the pain status for the entire population (that is, $1+2+2+1+1+4=11$ patients had a preoperative pain score of 10. Postoperatively, no patient had pain socres of 9 or 10). Numbers along horizontal and vertical axes refer to rating of pain $(0=$ no pain; $10=$ worst pain $)$.

To substantiate the patients' perception of pain relief, we analyzed their use of pain medication (Fig. 8). Detailed documentation of pain medication use was available in 61 of the 65 patients who presented with pain. The two patients who died postoperatively were not included, nor were two patients whose documentation did not adequately specify the type of medication they were taking. Analgesic medication usage was significantly reduced postoperatively ( $p<0.001$, Wilcoxon signed-rank test). Twenty-eight patients were able to decrease their class of pain medication by at least one category. Seventeen patients required no pain medication postoperatively, including three patients who had required intravenous or transdermal narcotics preoperatively. Twenty-nine patients showed no change in their medication category following the procedure, whereas four patients required an increase in their class of medication. 


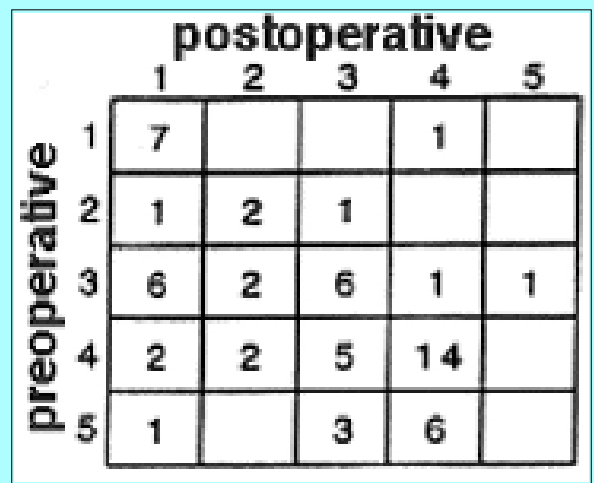

Fig. 8. Diagram indicating the relationship between preoperative and 1-month postoperative analgesic medication usage (see Table 2 for description of medication classification). Values within boxes indicate numbers of patients within each category. Numbers along horizontal and vertical axes refer to categories of medication.

Despite the high degree of pain relief achieved in our series, a large proportion of patients were still using narcotic pain medications at the time of their 1-month follow-up appointment. Of the 23 patients requiring pain medication from either Category 4 or 5 postoperatively (Fig. 8), five patients claimed to have greatly improved spinal column pain but required the pain medication for other bone metastases. Four patients required this type of pain medication for incisional or "thoracotomy" pain 1 month following the procedure, despite improvement in their spinal column pain. If we eliminate these nine patients, we are left with 14 patients who required strong narcotic analgesics postoperatively for pain related to their spinal column disease. Six of these patients had required intravenous narcotics, preoperatively, and their pain was managed well after surgery with oral narcotic medications. Seven patients continued to take the same type of analgesic, but they reported improved pain relief. The remaining patient who required strong narcotic medications following surgery reported no improvement in her pain management.

With the exception of the three patients who experienced complications related to embolization, 46 (67\%) of 69 patients presented with neurological dysfunction. Thirty-five (76\%) of these 46 neurologically impaired patients improved neurologically after surgery $(\mathrm{p}<0.001)$, with 27 patients improving at least one Frankel grade and 20 patients regaining normal neurological function (Fig. 9). Preoperatively, of these 46 neurologically impaired patients 33 were ambulatory but had weakness, and 13 were nonambulatory. Following surgery, 17 (52\%) of the 33 patients who had been ambulatory with weakness regained normal strength and $15(45 \%)$ remained ambulatory with weakness. One patient who developed a postoperative hematoma and had presented with profound weakness was unable to walk postoperatively (changed from Frankel D2b to Ca) despite evacuation of the hematoma. Of the 13 preoperatively nonambulatory patients, 10 regained ambulatory ability after surgery (three of these patients regained normal neurological function). The remaining three of the 13 patients remained nonambulatory following the operation.

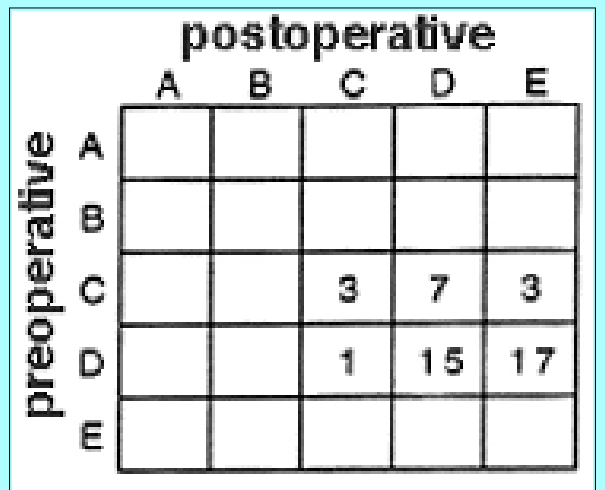

Fig. 9. Diagram indicating the relationship between preoperative and 1-month postoperative neurological assessment using the Frankel scale. This includes 46 patients who presented with neurological compromise. Values within boxes indicate numbers of patients within each category. 
Letters along horizontal and vertical axes refer to Frankel grades (see Table 3).

\section{DISCUSSION}

In the present study we attempt to provide a clear perspective of results that can be expected of anterior vertebral body resection and stabilization for spinal metastases that are limited to the thoracic region (Fig. 10).

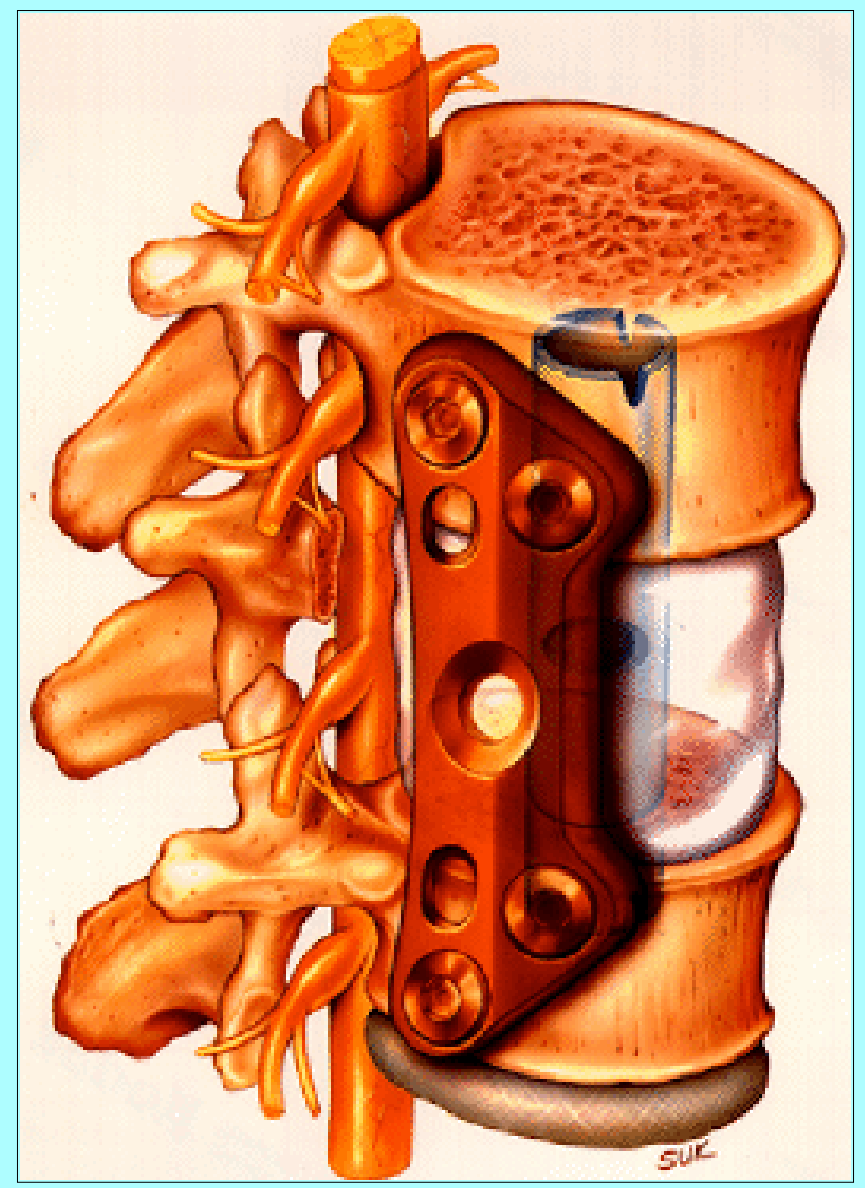

Fig. 10. Artist's rendering of thoracic vertebrectomy, reconstruction with methylmethacrylate, and placement of anterior locking plate and screw construct.

Previously published reports of major studies in which the anterior approach was used to remove spinal lesions from a large patient complement have included tumors located in other spinal regions.[20,35,39,40] This study is based on a patient population that was uniform in tumor location (thoracic) and tumor type (metastatic). A uniform surgical approach (transthoracic) was used in all patients, and all of them underwent reconstruction with methylmethacrylate and stabilization with anterior plating. We only included patients with thoracic spinal metastases and excluded those with paravertebral spinal lesions because spinal involvement by direct extension of tumors such as lung carcinomas and/or soft tissue sarcomas is likely to be associated with a poorer outcome than is seen for solitary spinal metastases. This is because surgery for paravertebral spinal lesions is more complex and requires lung resection at the same time; therefore, the risk of complications is not comparable to that for a more limited vertebrectomy procedure. Furthermore, in contrast with other large studies, we did not include lesions of the lumbar region because surgical decompression of the cauda equina by removal of lumbar metastases may be associated with a better outcome than is seen with thoracic decompression.

The region of the spinal column most frequently involved with metastases is the vertebral body, probably because of its large size relative to posterior elements and its high degree of vascularity. Epidural spinal cord compression thus usually results when tumors extend dorsally from the vertebral body into the spinal canal.[35] Typically, radiation therapy is used by oncologists as the first line of therapy for patients with metastatic spinal disease, and surgery is seldom considered for these patients before initiation of radiotherapy. The rationale for this stems from reports in which results from radiation therapy alone are compared with those from radiotherapy combined with 
laminectomy. Even though the surgical management of spinal metastases has evolved considerably over the years such that laminectomy alone is now infrequently proposed as a management option, results of studies based on the laminectomy procedure have led some to the incorrect conclusion that radiation therapy is as effective a treatment as surgery. Radiation therapy alone is reported to produce neurological improvement, on average, in $44 \%$ of patients with metastatic spinal disease, $[3,8,14,15,27,30]$ whereas laminectomy without stabilization followed by radiation therapy provides essentially the same improvement.[3,4,6,8,20,22,24,25,38]

The important point to consider is that laminectomy is not the proper surgical procedure on which to base such comparisons. Not only does it provide inadequate surgical exposure, as the bulk of the tumor compressing the spinal cord usually resides not in the posterior spinal elements but in the vertebral body, but the requisite removal of supporting spinal elements can produce or worsen spinal instability and create deformity, which may potentially worsen a patient's neurological status.

A review of published reports on the treatment of metastatic spinal tumors by laminectomy plus stabilization demonstrated an average neurological improvement rate of $72 \% .[5,7,10,17,19,28,30,33,34,36]$ These same studies also report significant pain reduction in more than of $80 \%$ of patients. Although use of laminectomy in decompressing the spinal cord is inferior to vertebrectomy because of the location of disease, addition of the stabilization procedure eliminates instability-related neurological deterioration and pain, thus resulting in a significant improvement in overall outcome. However, usually a two- to three-level laminectomy is needed for adequate decompression or transpedicular tumor removal, and spinal stabilization requires fixation of at least two spinal segments rostral and caudal to the laminectomy site (long segment fixation).

The transthoracic surgical approach for vertebrectomy has a number of advantages over the posterior approach. Because the anterior approach provides the best access to the disease-containing spinal elements, it provides for maximum decompression of the spinal cord and allows the surgeon to remove the tumor in a very expeditious fashion, thus theoretically limiting blood loss. Moreover, it allows for spinal reconstruction and stabilization that results in significant pain improvement in these patients, eliminating postoperative or preexisting spinal instability. In our series, $76 \%$ of the patients showed neurological improvement $(\mathrm{p}<0.001)$ and $77 \%$ of those who could not walk before undergoing surgery regained ambulatory capacity. We would like to note that it would be inappropriate to consider the neurological improvement observed in our study to be a result of prior radiation therapy or chemotherapy because the patients who presented to us as surgical candidates were considered to have experienced treatment failure by those modalities. Whereas postoperative neurological deterioration is unusual after transthoracic vertebrectomy (1.4\% in our series), it is seen in up to $20 \%$ of patients following laminectomy.[25,34,35]

One of the authors of the present study has also described a technique for posterior vertebrectomy, reconstruction, and instrumentation that can be used for a certain subset of patients who are poor candidates for the transcavitary approach due to their more compromised overall medical condition or who have both anterior and posterior column involvement of the thoracic and lumbar spine.[1] Of 110 patients undergoing surgery for spinal metastases by posterior approaches at UTMDACC from 1989 to 1995, only 25 were deemed appropriate candidates for this operation. Akeyson and McCutcheon[1] considered this approach reasonable for patients who were at high risk or who had circumferential tumors, but as expected, they found a high incidence of wound infection (three [12\%] of 25 patients), persistent cerebrospinal fluid leak (four [16\%] of 25 patients), and graft dislodgement (four [16\%] of 25 patients). Furthermore, patients who underwent this procedure had a longer average hospital stay (15 days) than those in our present (transthoracic) series (10 days) and a poorer 12-month survival rate (12\% compared with $62 \%$ in this series). Thus, our current advocacy of anterior vertebrectomy does not reflect a change in philosophy at UTMDACC since publication of the paper by Akeyson and McCutcheon. Indeed, we feel that the transthoracic approach is the treatment of choice for spinal metastatic disease in patients who primarily have anterior column involvement and are able to tolerate a transthoracic approach.

Pain improvement has been reported for 80 to $90 \%$ of patients in most series in which vertebrectomy plus stabilization are used.[20,32,35,40] This figure was $92 \%$ in our series, and we were able to substantiate the 
postoperative pain improvement reported by our patients ( $p<0.001$ as assessed by a visual analog scale) by a significant reduction in their overall usage of analgesic medications $(\mathrm{p}<0.001)$.

Despite the fact that the majority of patients who undergo a transthoracic vertebrectomy will have already received radiation treatment, the risk of infection and/or other wound-healing problems is exceedingly small in cases in which this procedure is performed (superficial wound infections in two of 72 patients in our series). On the other hand, the rate of such complications has been reported to be as high as $28 \%$ in patients who have undergone a laminectomy after radiation therapy.[35]

Overall, the 30-day mortality rate for patients who have undergone laminectomy with stabilization has been reported to range from 3 to $8 \%$, which compares favorably with that for vertebrectomy followed by stabilization, which is less than $8 \%$ (3\% in our series) for the majority of series, although a few authors have reported mortality rates of 20 to $30 \%$.[16,20,29,30,35,36,39-41]

Table 5 summarizes the published reports of predominantly anterior vertebral body resection for spinal tumors. A comparison of our results with these previously published results is difficult because the other studies included tumors at all spinal levels and considered metastatic tumors together with primary spinal tumors and tumors extending directly from contiguous structures. The indications for the various reconstruction techniques and instrumentation used in other studies are not always clear.

\section{TABLE 5}

SUMMARY OF USE OF VERTEBRECTOMV FOR THE TREATMENT OF METASTATK TUMORS*

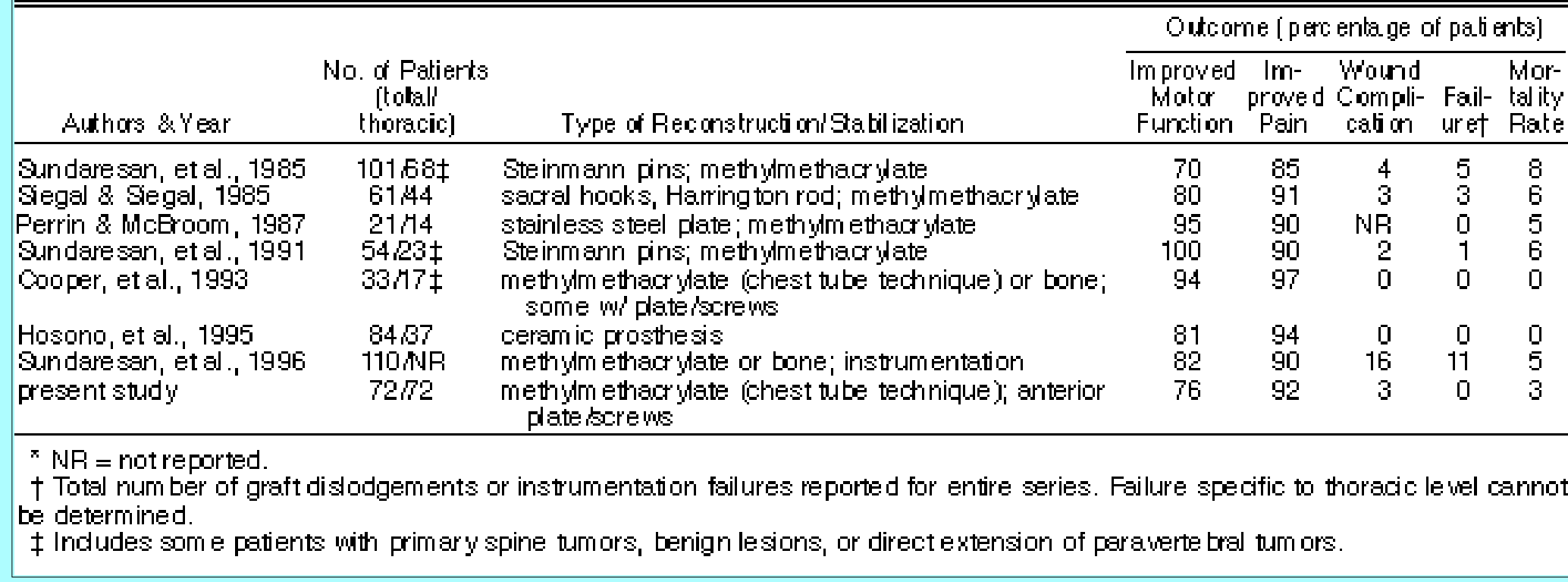

Sundaresan, et al.,[40] treated 101 patients for spinal tumors by the anterior approach; 68 of their patients had thoracic involvement. Because some of these 68 patients had spinal involvement by direct extension of paravertebral tumors, it is not possible to discern the exact number of spinal metastases. In a more recent article, Sundaresan and colleagues[39] report the results of a prospective study involving 54 patients with either primary or metastatic spinal tumors, 23 of which involved the thoracic spine. All of the patients had improved motor function postoperatively and pain was relieved in $90 \%$. It is not clear how many of these patients underwent a transthoracic vertebrectomy procedure.

Similarly, good neurological recovery and pain relief were obtained by Siegal and Siegal.[35] They reported their results for vertebral body resections performed in 61 patients with malignant tumors compressing the spinal cord, 44 of which were located in the thoracic region. Eleven of these tumors were approached via a costotransversectomy and 33 via a transthoracic vertebrectomy. Hosono, et al.,[20] used a ceramic prosthesis to treat 84 patients with spinal metastases; 37 of their patients had thoracic involvement. Again, improvement in motor function and pain relief were reported to be in the 80 to $90 \%$ range. 
Recent changes in the health care environment have placed an emphasis on the economics of medicine and the importance of becoming cost effective. The average cost of caring for a paraplegic patient is $\$ 152,396$ for the 1st year and $\$ 15,507$ for each subsequent year, as reported by the National Spinal Cord Injury Statistical Center (University of Alabama, Birmingham, AL).[2] Although it is difficult to measure the true costs of these procedures, improvement in quality of life (decreased pain and improved neurological status) and a relatively short hospital stay (a mean of 10 days in our series) suggest that surgery in this situation is relatively cost effective.

\section{CONCLUSIONS}

The transthoracic approach with vertebrectomy followed by spinal stabilization for patients with metastatic spinal disease facilitates tumor excision by optimizing exposure in the diseased spinal region. In addition, spinal reconstruction can be effectively performed by reconstituting the anterior spinal column using methylmethacrylate as described. Stabilization is achieved by using a thoracic plate and screw construct that extends only one segment above and below the vertebrectomy site. With this procedure, the rates of neurological improvement and pain relief are high and the risk of wound complications is very low, a serious consideration for those who require additional radiation therapy. Overall, the rate of mortality from the procedure compares favorably to that of posterior procedures. We recommend aggressive resection of metastatic disease in the thoracic spine by a combined team of thoracic and spinal surgeons to enhance the patient's quality of life and recovery of independent ambulation.

\section{References}

1. Akeyson EW, McCutcheon IE: Single-stage posterior vertebrectomy and replacement combined with posterior instrumentation for spinal metastasis. J Neurosurg 85:211-220, 1996

2. Anonymous: Cost of injury. The Spinal Cord. Neurotrauma Law Nexus (website).

URL:http://www.neurolaw.com/spine.html

3. Bach F, Larsen BH, Rohde K, et al: Metastatic spinal cord compression. Occurrence, symptoms, clinical presentations and prognosis in 398 patients with spinal cord compression. Acta Neurochir 107:37-43, 1990

4. Baldini M, Tonnarelli GP, Princi L, et al: Neurological results in spinal cord metastases. Neurochirurgia 22:159-65, 1979

5. Bauer HCF: Posterior decompression and stabilization for spinal metastases. Analysis of sixty-seven consecutive patients. J Bone Joint Surg (Am) 79:514-522, 1997

6. Brady LW, Antoniades J, Prasasvinichai S, et al: The treatment of metastatic disease of the nervous system by radiation therapy, in Seydel HG (ed): Tumors of the Nervous System. New York: John Wiley \& Sons, 1975, pp $176-189$

7. Brunon J, Sautreaux JL, Sindou M, et al: Apport de l'ostéosynthèse postérieure dans le traitement des tumeurs du rachis. Neurochirurgie 21:435-446, 1975

8. Constans JP, de Divitiis E, Donzelli R, et al: Spinal metastases with neurological manifestations. Review of 600 cases. J Neurosurg 59:111-118, 1983

9. Cooper PR, Errico TJ, Martin R, et al: A systematic approach to spinal reconstruction after anterior decompression for neoplastic disease of the thoracic and lumbar spine. Neurosurgery 32:1-8, 1993

10. DeWald RL, Bridwell KH, Prodromas C, et al: Reconstructive spinal surgery as palliation for metastatic malignancies of the spine. Spine 20:21-26, 1985

11. Dunn RC Jr, Kelly WA, Wohns RNW, et al: Spinal epidural neoplasia. A 15-year review of the results of surgical therapy. J Neurosurg 52:47-51, 1980 
12. Errico TJ, Cooper PR: A new method of thoracic and lumbar body replacement for spinal tumors: technical note. Neurosurgery 32:678-681, 1993

13. Frankel HL, Hancock DO, Hyslop G, et al: The value of postdural reduction in the initial management of closed injuries in the spine with paraplegia and tetraplegia. I. Comprehensive management and research. Paraplegia 7:179-192, 1969

14. Gilbert RW, Kim JH, Posner JB: Epidural spinal cord compression from metastatic tumor: diagnosis and treatment. Ann Neurol 3:40-51, 1978

15. Greenberg HS, Kim JH, Posner JB: Epidural spinal cord compression from metastatic tumor: results with a new treatment protocol. Ann Neurol 8:361-366, 1980

16. Hall DJ, Webb JK: Anterior plate fixation in spine tumor surgery. Indications, techniques, and results. Spine 16 (Suppl 3):S80-S83, 1991

17. Hansebout RR, Blomquist GA Jr: Acrylic spinal fusion. A 20-year clinical series and technical note. J Neurosurg 53:606-612, 1980

18. Harrington KD: Anterior cord decompression and spinal stabilization for patients with metastatic lesions of the spine. J Neurosurg 61:107-117, 1984

19. Heller M, McBroom RJ, MacNab T, et al: Treatment of metastatic disease of the spine with posterolateral decompression and Luque instrumentation. Neuroorthopedics 2:70-74, 1986

20. Hosono N, Yonenobu K, Fuji T, et al: Vertebral body replacement with a ceramic prosthesis for metastatic spinal tumors. Spine 20:2454-2462, 1995

21. Kaplan EL, Meier P: Nonparametric estimation from incomplete observations. J Am Stat Assoc 53:457-481, 1958

23. Klein HJ, Richter HP, Schäfer M: Extradural spinal metastases--a retrospective study of 197 patients. Adv Neurosurg 12:36-43, 1984

23. Kollman H, Diemath HE, Strohecker J, et al: Spinal metastases as the first manifestation. Adv Neurosurg 12:44-46, 1984

24. Landis SH, Murray T, Bolden S, et al: Cancer statistics, 1998. CA Cancer J Clin 48 6-29, 1998

25. Landmann C, Hünig R, Gratzl O: The role of laminectomy in the combined treatment of metastatic spinal cord compression. Int J Radiat Oncol Biol Phys 24:627-631, 1992

26. Livingston KE, Perrin RG: The neurosurgical management of spinal metastases causing cord and cauda equina compression. J Neurosurg 49:839-843, 1978

27. Maranzano E, Latini P: Effectiveness of radiation therapy without surgery in metastatic spinal cord compression: final results from a prospective trial. Int J Radiat Oncol Biol Phys 32:959-967, 1995

28. Miles J, Banks AJ, Dervin E, et al: Stabilisation of the spine affected by malignancy. J Neurol Neurosurg Psychiatry 47:897-904, 1984

29. Moore AJ, Uttley D: Anterior decompression and stabilization of the spine in malignant disease. Neurosurgery 24:713-717, 1989

30. Obbens E, Kim JH, Thaler H, et al: Metronidazole as a radiation enhancer in the treatment of metastatic epidural spinal cord compression. J Neurooncol 2:99-104, 1984 
31. Olerud C, Jonsson B: Surgical palliation of symptomatic spinal metastases. Acta Orthop Scand 67:513-522, 1996

32. Onimus M, Schraub S, Bertin D, et al. Surgical treatment of vertebral metastasis. Spine 11:883-891, 1986

33. Overby MC, Rothman AS: Anterolateral decompression for metastatic epidural spinal cord tumors. Results of a modified costotransversectomy approach. J Neurosurg 62:344-348, 1985

34. Perrin RG, McBroom RJ: Anterior versus posterior decompression for symptomatic spinal metastasis. Can J Neurol Sci 14:75-80, 1987

35. Siegal T, Siegal T: Surgical decompression of anterior and posterior malignant epidural tumors compressing the spinal cord: a prospective study. Neurosurgery 17:424-432, 1985

36. Slatkin NE, Posner JB: Management of spinal epidural metastases. Clin Neurosurg 30:698-716, 1982

37. Solini A, Paschero B, Orsini G, et al: The surgical treatment of metastatic tumors of the lumbar spine. Ital J Orthop Traumatol 11:427-442, 1985

38. Stark RJ, Henson RA, Evans SJW: Spinal metastases: a retrospective survey from a general hospital. Brain 105:189-213, 1982

39. Sundaresan N, Digiacinto GV, Hughes JEO, et al: Treatment of neoplastic spinal cord compression: results of a prospective study. Neurosurgery 29:645-650, 1991

40. Sundaresan N, Galicich JH, Lane JM, et al: Treatment of neoplastic epidural cord compression by vertebral body resection and stabilization. J Neurosurg 63:676-684, 1985

41. Sundaresan N, Steinberger AA, Moore F, et al: Indications and results of combined anterior-posterior approaches for spine tumor surgery. J Neurosurg 85:438-446, 1996

42. Walsh GL, Gokaslan ZL, McCutcheon IE, et al: Anterior approaches to the thoracic spine in patients with cancer: indications and results. Ann Thorac Surg 64:1611-1618, 1997

Manuscript received March 23, 1998.

Accepted in final form June 2, 1998.

Address reprint requests to: Ziya L. Gokaslan, M.D., Department of Neurosurgery, Box 64, The University of Texas M. D. Anderson Cancer Center, 1515 Holcombe Boulevard, Houston, Texas 77030. 